\title{
The evaluating of pregnancy-associated plasma protein-A with the likelihood of small for gestational age
}

\author{
Maryam Sadat Hoseini, MD' , Samaneh Sheibani, MD' , Mehrdad Sheikhvatan, MD, PhD ${ }^{2,3}$ \\ ${ }^{1}$ Department of Obstetrics and Gynecology, Preventative Gynecology Research Center, Imam Hossein Hospital, Shahid Beheshti University of Medical \\ Sciences, ${ }^{2}$ Pars Advanced and Minimally Invasive Medical Manners Research Center, Pars Hospital, Iran University of Medical Sciences, Tehran, Iran; \\ ${ }^{3}$ Heidelberg University Hospital, University of Heidelberg, Heidelberg, Germany
}

\section{Objective}

Recently, strong evidences were obtained on the association between low pregnancy-associated plasma protein-A (PAPP-A) levels in the first trimester and poor outcomes of pregnancy.

\section{Methods}

This cross-sectional study was conducted on all pregnant women who were referred to the Obstetrics and Gynecology Clinic at Imam Hossein Hospital in Tehran, Iran in 2014. Women were asked to attend clinical examinations and screening at 11-14 weeks of gestation.

\section{Results}

Based on the definition, $14.5 \%$ of neonates found to be small for gestational age (SGA). There was a strong association between PAPP-A levels and birth weight. The mean PAPP-A level in the mothers of neonates who were SGA was significantly lower than those without this poor outcome. Based on the receiver operating characteristic curve analysis, serum PAPP-A level was a main determinant in the prediction of SGA neonates.

\section{Conclusion}

The serum PAPP-A level at 11-13 weeks of gestation can effectively predict the increased risk for fetal growth retardation. In patients in this study, the best cutoff value for PAPP-A was 0.75 MOM, which signifies that lower levels of this marker can predict fetal growth restriction with high sensitivity and specificity.

Keywords: Pregnancy; Plasma protein-A; Gestational age

\section{Introduction}

Pregnancy-associated plasma protein-A (PAPP-A) is a zincbound metalloproteinase from the super family of metalloproteases [1]. PAPP-A is a large glycoprotein made up of the placenta, decidua, and fetuses; however, the main source of this protein in pregnancy is placental syncytiotrophoblast [2-7]. Various functions of PAPP-A have been described. Primarily, PAPP-A releases insulin-like growth factor (IGF) via the breakdown of IGF-binding protein-4 [8-12]. Thus, PAPP-A facilitates the function of IGF of accelerating and augmenting placental growth. Local IGF secretion plays an important role in increasing mitosis and cellular differentiation as well as in controlling trophoblastic invasion of the decidua [13].
Received: 2018.12.30. Revised: 2019.05.09. Accepted: 2019.05.28.

Corresponding author: Samaneh Sheibani, MD

Department of Obstetrics and Gynecology, Preventative

Gynecology Research Center, Imam Hossein Hospital, Shahid Beheshti University of Medical Sciences, Shahid Madani Street,

Tehran 1617763141, Iran

E-mail: S.Sheibani.PGRC@gmail.com

https://orcid.org/0000-0002-8658-1867

Articles published in Obstet Gynecol Sci are open-access, distributed under the terms of the Creative Commons Attribution Non-Commercial License (http://creativecommons. org/licenses/by-nc/3.0/) which permits unrestricted non-commercial use, distribution, and reproduction in any medium, provided the original work is properly cited.

Copyright $\odot 2020$ Korean Society of Obstetrics and Gynecology 


\title{
Obstetrics \& Gynecology Science
}

\author{
Vol. 63, No. 3, 2020
}

The role of IGFs in controlling fetal growth is important as they regulate the absorption of amino acids and glucose in the trophoblast. Currently, it is hypothesized that low PAPPA levels in the maternal serum represent a decrease in the regional levels of the protein, which results in a reduction in active IGF levels. Thus, inadequate free IGF levels, which affect the development of the embryo, may lead to other complications of pregnancy, such as stillbirth, risk of small for gestational age (SGA) neonates, preeclampsia, and premature delivery $[14,15]$. In addition, other functions of PAPP-A include prevention of fetal targeting by the mother's immune system, uterine mineralization, and angiogenesis [16]. Pregnant women with PAPP-A levels less than 0.45 multiples of the median (MoM) have been significantly associated with increased risk of intrauterine growth restriction, SGA, premature labor, preeclampsia, and stillbirth [17]. In total, low PAPP-A levels in the first trimester of pregnancy have been strongly associated with poor outcomes [18]. In other words, Iow PAPP-A levels are indicative of poor primary placenta, leading to serious complications such as embryonic growth restriction, fetal death, preterm labor, and preeclampsia in the third trimester. Considering the heavy economic and social impact of chromosomal abnormalities and complications of pregnancy and childbirth for the community and given the fact that many of these complications are preventable, we attempted to examine the association between serum PAPPA levels in the first trimester of pregnancy and the likelihood of SGA neonates.

\section{Materials and methods}

This cross-sectional study was conducted on all pregnant women who were referred to the Obstetrics and Gynecology Clinic at Imam Hossein Hospital in Tehran, Iran in 2014. At first, all participants gave written/verbal informed consent before commencement of the study, following which a complete biography of the mothers was obtained. Data on maternal age, gestational age, parity, and history of pregnancies with complications were also recorded. The participants were asked to attend clinical examinations and screening at 11-14 weeks of gestation during which ultrasonography performed and blood samples were taken to measure common biochemical indices and markers such as $\beta$-HCG. In addition to the usual tests, we measured PAPP-A levels in the blood samples of these individuals. The cases with fetal crownrump length ranging from 45 to $84 \mathrm{~mm}$ were asked to provide written informed consent if they wished to participate in the study. CRL values were converted to gestational age (GA) using $Z$ score, and PAPP-A levels less than $5 \%$ in each GA were considered as low. Mothers were then followed up until delivery. During this period, all routine healthcare measures were performed for these mothers and any abnormalities were treated. In this study, the results were determined based on outcome of the delivery. In cases of presence of a disorder other than SGA fetuses/neonates during pregnancy or at the time of delivery, the mother was excluded from the study. Finally, the data were statistically analyzed. The institutional ethics committee of the Preventative Gynecology Research Center (PGRC) at Shahid Beheshti University of Medical Sciences approved the study protocol. For analyses, results were presented as mean \pm standard deviation (SD) for quantitative variables and as absolute frequencies and percentages for categorical variables. Normality of the data was analyzed using the Kolmogorov-Smirnoff test. Categorical variables were compared using chi-square test or Fisher's exact test when more than $20 \%$ of cells with expected count of less than 5 were observed. The quantitative variables were also compared with $t$-test or Mann-Whitney $U$ test. The value of PAPP-A to predict SGA neonates was assessed using the receiver operating characteristic (ROC) curve analysis. Multivariable logistic regression model was also used to determine the value of low PAPP-A levels in predicting SGA neonates using baseline characteristics. For statistical analyses, SPSS version 16.0 for Windows (SPSS Inc., Chicago, IL, USA) was used. $P$-values of 0.05 or less were considered significant.

\section{Results}

In total, 715 pregnant women were assessed. The mean age of participants was $27.88 \pm 5.97$ years (range, 17-38 years). Regarding gestational age at the time of screening, 34.5\% were in the 11 th week, $49.1 \%$ in the 12 th week, and $16.4 \%$ in the 13th week of pregnancy. The mean body weight of the participants was $68.90 \pm 12.55 \mathrm{~kg}$ (range, 47-105 kg). Average birth weight of neonates was $3,100.91 \pm 553.82 \mathrm{~g}$ (range, 1,700-4,000 g). The mean PAPP-A level at the time of screening was $1.21 \pm 0.66$ (range, 0.28-3.37) (Table 1). Based on the definition of weight less than 10th percentile 


\section{Obstetrics \& Gynecology Science}

Maryam Sadat Hoseini, et al. Pregnancy-associated plasma protein-A

based on gestational age, $14.5 \%$ of neonates were found to be SGA. There was no difference in the mean weight of mothers with and without SGA neonates $(30.08 \pm 8.63$ years vs. $27.51 \pm 5.43$ years, $P=0.439$ ). No difference was also found in the mean weight of mothers with and without neonates who were SGA $(73.81 \pm 18.21 \mathrm{~kg}$ vs. $68.06 \pm 11.39$ $\mathrm{kg}, P=0.413)$. The overall prevalence of fetuses who were SGA at 11,12 , and 13 weeks of pregnancy was $26.3 \%$, $3.7 \%$, and $22.2 \%$, respectively with no significant difference $(P=0.078)$. There was a strong association between PAPP-A levels and birth weight ( $r=0.442, P=0.001)$ (Fig. 1). The mean PAPP-A level in mothers of neonates who were SGA was significantly lower than that in women with normal delivery

Table 1. Baseline characteristics of the study population

\begin{tabular}{lc}
\hline Characteristics & Values \\
\hline Mean age (yr) & $27.88 \pm 5.97$ \\
Gestational age at screening (wk) & $34.5 \%$ \\
Eleventh week & $49.1 \%$ \\
Twelfth week & $16.4 \%$ \\
Thirteenth week & $3,100.91 \pm 553.82$ \\
Mean birth weight of neonates & $1.21 \pm 0.66$ \\
The mean level of PAPP-A on screening & \\
time & $14.5 \%$ \\
The prevalence of SGA &
\end{tabular}

PAPP-A, pregnancy-associated plasma protein-A; SGA, small for gestational age.

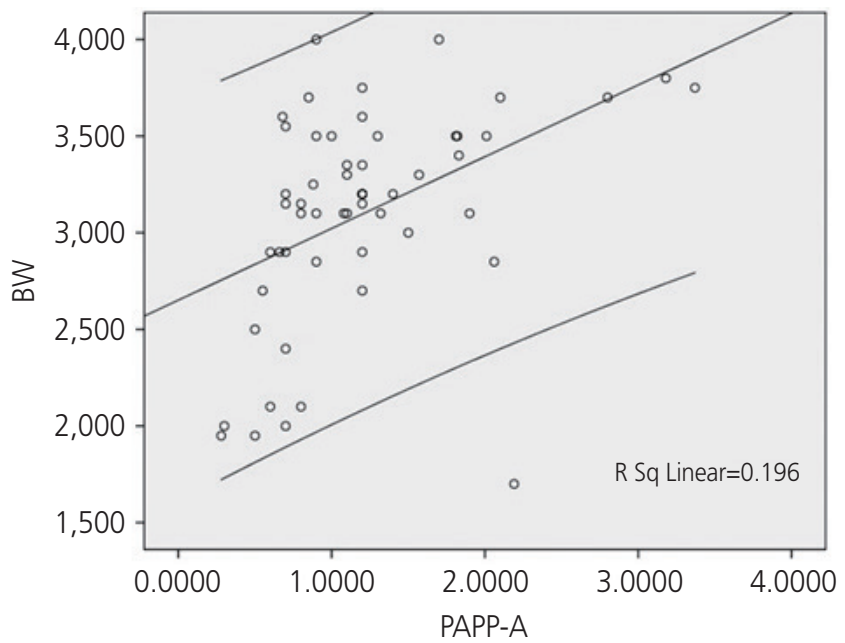

Fig. 1. The association between pregnancy-associated plasma protein-A (PAPP-A) level and birth weight (BW). children $(0.76 \pm 0.61$ vs. $1.29 \pm 0.64, P=0.035)$. Based on the ROC curve analysis (Fig. 2), the serum PAPP-A level was a main determinant in the prediction of SGA neonates (Area under the curve $=0.811, P=0.005)$. The best cutoff value for PAPP-A to discriminate between SGA neonates and those with normal weight was 0.75 yielding a sensitivity of $80.9 \%$ and a specificity of $85.0 \%$. According to the multivariable logistic regression model and with the presence of baseline variables including maternal age, weight, and gestational age, decreased PAPP-A levels could effectively predict the increased likelihood of SGA neonates (odds ratio, 12.347; 95\% confidence interval, 0.012-165.917; $P=0.048$ ).

\section{Discussion}

Two methods of clinical examination and arterial Doppler are not very sensitive and precise for predicting fetal growth restriction (FGR) and may lead to over-estimation of cases that are SGA. In this regard, the use of biochemical markers (such as cystatin C, macrophage migration inhibitory factor,

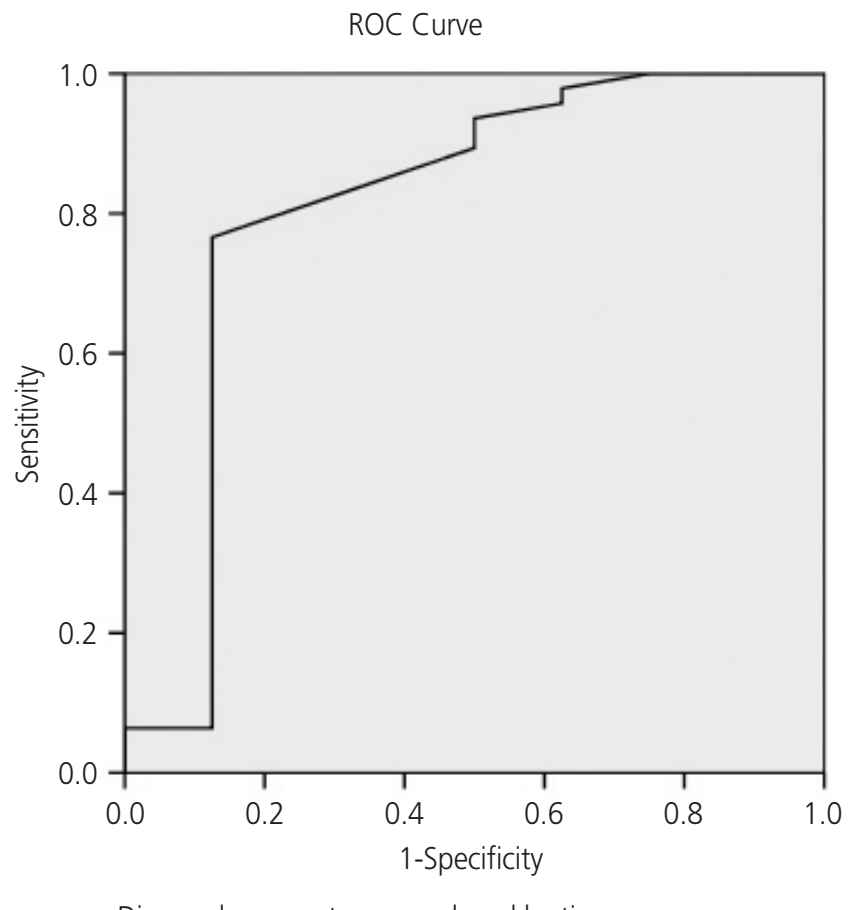

Diagonal segments are produced by ties.

Fig. 2. The receiver operating characteristic (ROC) curve analysis to determine the value of pregnancy-associated plasma protein-A (PAPP-A) to predict small for gestational age (SGA). 


\section{Obstetrics \& Gynecology Science}

Vol. 63, No. 3, 2020

plasminogen activator inhibitor 2, and PAPP-A), maternal medical history (history of smoking, parity, body mass index, and increased systolic blood pressure), and some dynamic vascular parameters such as uterine artery pulsatility during the first or second trimester have been considered as predictors of FGR. Accordingly, in recent years, experts have considered the assessment of serum free $\beta-H C G$ and PAPPA levels in the prediction of FGR. Some studies have reported that increased $\beta-H C G$ levels and decreased PAPP-A levels are critical in predicting FGR. However, a few important points are still questionable. First, the power and diagnostic capability of these biomarkers have not been tangibly considered in the prediction of FGR. Second, the best cut-off point for these biomarkers in predicting FGR in different communities may vary and should, therefore, be considered in future studies. The present study aimed to determine the capability and value of PAPP-A in predicting FGR in a sample of Iranian population. First, our study showed that the assessment of serum PAPP-A levels was effective to predict FGR with high sensitivity and specificity. Second, based on the results of the ROC curve analysis, the best cutoff point for PAPP-A was 0.75; thus, lower levels of this marker strongly correlated with high risk of FGR. However, the obtained cutoff value in our study was notably higher than that previously reported in some studies (0.75 vs. 0.30). As reported by Agarwal et al. [19] in 2017 , with a cutoff value of 0.45 , the specificity and positive predictive value of PAPP-A for FGR were $92.6 \%$ and $56.2 \%$, respectively. However, in another study by Sung et al. [20] in 2017, the best cut-off value of PAPP-A for predicting a SGA infant was $1.06 \mathrm{MoM}$, which was significantly higher than that reported in the present study. This discrepancy might be caused by several factors such as the difference in the tools used for measurement of PAPP-A, the effect of genomic factors, and different gestational ages. In general, there is consensus among all studies with regard to the capability of PAPP-A in the prediction of FGR. In a study by Hansen et al. [21], low PAPP-A levels were associated with the risk of SGA neonates. In a study by D'Antonio et al. [22], serum PAPP-A levels were significantly lower in women with SGA children than in those with normal delivery children. Another study by Loncar et al. [23] reported similar findings. In a survey by Kirkegaard et al. [24], PAPP-A levels less than 0.4 with a growth index less than 10 percentile were accompanied with an increased risk of SGA neonates up to 5.8-fold. Salvig et al. [25] reported that the growth rate of infants from the first to second trimester significantly correlated with PAPP-A levels. In a study by Fox and Chasen [26], PAPP-A levels below the fifth percentile was associated with an increased rate of FGR in the third trimester, preterm birth, neonatal intensive care unit admission, intrauterine or neonatal death, smaller median birth weight, and earlier median gestational age at delivery. They also showed that PAPP-A values below the 10th percentile and the 25th percentile were associated with poor outcomes. Finally, Carbone et al. [27] indicated that PAPPA below the 5th percentile had the highest sensitivity with a specificity of $82.1 \%$ for screening of SGA neonates.

In conclusion, the measurement of serum PAPP-A levels at 11-13 weeks of gestation can effectively predict the increased risk of SGA neonates. In patients in the present study, the best cutoff value for PAPP-A was 0.75 , which signifies that lower levels of this marker can predict SGA with high sensitivity and specificity.

\section{Conflict of interest}

No potential conflict of interest relevant to this article was reported.

\section{Ethical approval}

The study was approved by the Institutional Review Board of Shahid Beheshti University of Medical Sciences and performed in accordance with the principles of the Declaration of Helsinki.

\section{Patient consent}

The patients provided written informed consent for the publication and the use of their images.

\section{References}

1. Kagan KO, Wright $D$, Valencia C, Maiz N, Nicolaides KH. Screening for trisomies 21, 18 and 13 by maternal age, fetal nuchal translucency, fetal heart rate, free beta-hCG and pregnancy-associated plasma protein-A. Hum Re- 


\section{Obstetrics \& Gynecology Science}

Maryam Sadat Hoseini, et al. Pregnancy-associated plasma protein-A

prod 2008;23:1968-75.

2. Kagan KO, Wright D, Spencer K, Molina FS, Nicolaides $\mathrm{KH}$. First-trimester screening for trisomy 21 by free betahuman chorionic gonadotropin and pregnancy-associated plasma protein-A: impact of maternal and pregnancy characteristics. Ultrasound Obstet Gynecol 2008;31:493502.

3. Ong CY, Liao AW, Spencer K, Munim S, Nicolaides KH. First trimester maternal serum free $\beta$ human chorionic gonadotrophin and pregnancy associated plasma protein $A$ as predictors of pregnancy complications. BJOG 2000;107:1265-70.

4. Yaron $Y$, Heifetz S, Ochshorn Y, Lehavi O, Orr-Urtreger A. Decreased first trimester PAPP-A is a predictor of adverse pregnancy outcome. Prenat Diagn 2002;22:778-82.

5. Smith GC, Stenhouse EJ, Crossley JA, Aitken DA, Cameron $A D$, Connor JM. Early pregnancy levels of pregnancyassociated plasma protein a and the risk of intrauterine growth restriction, premature birth, preeclampsia, and stillbirth. J Clin Endocrinol Metab 2002;87:1762-7.

6. Dugoff L, Hobbins JC, Malone FD, Porter TF, Luthy D, Comstock $\mathrm{CH}$, et al. First-trimester maternal serum PAPP-A and free-beta subunit human chorionic gonadotropin concentrations and nuchal translucency are associated with obstetric complications: a population-based screening study (the FASTER Trial). Am J Obstet Gynecol 2004;191:1446-51.

7. Spencer K, Yu CK, Cowans NJ, Otigbah C, Nicolaides $\mathrm{KH}$. Prediction of pregnancy complications by first-trimester maternal serum PAPP-A and free $\beta-h C G$ and with second-trimester uterine artery Doppler. Prenat Diagn 2005;25:949-53.

8. Pilalis A, Souka AP, Antsaklis P, Daskalakis G, Papantoniou N, Mesogitis $S$, et al. Screening for pre-eclampsia and fetal growth restriction by uterine artery Doppler and PAPP-A at 11-14 weeks' gestation. Ultrasound Obstet Gynecol 2007;29:135-40.

9. Spencer K, Cowans NJ, Chefetz I, Tal J, Meiri H. Firsttrimester maternal serum PP-13, PAPP-A and secondtrimester uterine artery Doppler pulsatility index as markers of pre-eclampsia. Ultrasound Obstet Gynecol 2007;29:128-34.

10. Plasencia W, Maiz N, Bonino S, Kaihura C, Nicolaides $\mathrm{KH}$. Uterine artery Doppler at $11+0$ to $13+6$ weeks in the prediction of pre-eclampsia. Ultrasound Obstet Gy- necol 2007;30:742-9.

11. von Dadelszen P, Magee LA, Roberts JM. Subclassification of preeclampsia. Hypertens Pregnancy 2003;22:1438.

12. Witlin GA, Saade GR, Mattar FM, Sibai BM. Predictors of neonatal outcome in women with severe pre-eclampsia or eclampsia between 24 and 33 weeks' gestation. Am J Obstet Gynecol 1999;1:S19.

13. Irgens HU, Reisaeter L, Irgens LM, Lie RT. Long term mortality of mothers and fathers after pre-eclampsia: population based cohort study. BMJ 2001;323:1213-7.

14. Snijders RJ, Noble P, Sebire N, Souka A, Nicolaides $\mathrm{KH}$. UK multicentre project on assessment of risk of trisomy 21 by maternal age and fetal nuchal-translucency thickness at 10-14 weeks of gestation. Lancet 1998;352:343-6.

15. Spencer K, Spencer CE, Power M, Dawson C, Nicolaides $\mathrm{KH}$. Screening for chromosomal abnormalities in the first trimester using ultrasound and maternal serum biochemistry in a one-stop clinic: a review of three years prospective experience. BJOG 2003;110:281-6.

16. Nicolaides KH, Spencer K, Avgidou K, Faiola S, Falcon O. Multicenter study of first-trimester screening for trisomy 21 in 75821 pregnancies: results and estimation of the potential impact of individual risk-orientated two-stage first-trimester screening. Ultrasound Obstet Gynecol 2005;25:221-6.

17. Ciobanu A, Rouvali A, Syngelaki A, Akolekar R, Nicolaides $\mathrm{KH}$. Prediction of small for gestational age neonates: screening by maternal factors, fetal biometry, and biomarkers at 35-37 weeks' gestation. Am J Obstet Gynecol 2019;220:486.e1-486.e11.

18. McCowan LM, Thompson JM, Taylor RS, Baker PN, North RA, Poston $L$, et al. Prediction of small for gestational age infants in healthy nulliparous women using clinical and ultrasound risk factors combined with early pregnancy biomarkers. PLoS One 2017;12:e0169311.

19. Agarwal R, Kumari R, Mehndiratta M, Radhakrishnan G, Faridi MM, Chandra N. Pregnancy-associated plasma protein A levels in late first trimester pregnancies with small-for-gestational age neonates: a prospective casecontrol study. J Obstet Gynaecol India 2017;67:247-52.

20. Sung KU, Roh JA, Eoh KJ, Kim EH. Maternal serum placental growth factor and pregnancy-associated plasma protein A measured in the first trimester as parameters 


\section{Obstetrics \& Gynecology Science}

Vol. 63, No. 3, 2020

of subsequent pre-eclampsia and small-for-gestationalage infants: a prospective observational study. Obstet Gynecol Sci 2017;60:154-62.

21. Hansen $Y B$, Myrhøj $V$, Jørgensen FS, Oxvig C, Sørensen $S$. First trimester PAPP-A2, PAPP-A and $h C G \beta$ in smallfor-gestational-age pregnancies. Clin Chem Lab Med 2016:54:117-23.

22. D'Antonio F, Rijo C, Thilaganathan C, Akolekar B, Khalil $R$, Papageourgiou $A$, et al. Association between firsttrimester maternal serum pregnancy-associated plasma protein-A and obstetric complications. Prenat Diagn 2013;33:839-47.

23. Loncar $D$, Varjacić $M$, Arsenijević S. Significance of pregnancy-associated plasma protein A (PAPP-A) concentration determination in the assessment of final outcome of pregnancy. Vojnosanit Pregl 2013;70:46-50.

24. Kirkegaard I, Henriksen TB, Uldbjerg N. Early fetal growth, PAPP-A and free $\beta-h C G$ in relation to risk of delivering a small-for-gestational age infant. Ultrasound Obstet Gynecol 2011;37:341-7.

25. Salvig JD, Kirkegaard I, Winding TN, Henriksen TB, Tørring $N$, Uldbjerg N. Low PAPP-A in the first trimester is associated with reduced fetal growth rate prior to gestational week 20. Prenat Diagn 2010;30:503-8.

26. Fox NS, Chasen ST. First trimester pregnancy associated plasma protein-A as a marker for poor pregnancy outcome in patients with early-onset fetal growth restriction. Prenat Diagn 2009;29:1244-8.

27. Carbone JF, Tuuli MG, Bradshaw R, Liebsch J, Odibo $A O$. Efficiency of first-trimester growth restriction and low pregnancy-associated plasma protein-A in predicting small for gestational age at delivery. Prenat Diagn 2012;32:724-9. 